\title{
Stress-Responsive Periplasmic Chaperones in Bacteria
}

\author{
Hyunhee $\mathrm{Kim}^{1,2 t}$, Kevin Wu $\mathrm{u}^{2,3+}$ and Changhan Lee ${ }^{1 *}$ \\ ${ }^{1}$ Department of Biological Sciences, Ajou University, Suwon, South Korea, ${ }^{2}$ Molecular, Cellular, and Developmental Biology, \\ Howard Hughes Medical Institute, University of Michigan, Ann Arbor, MI, United States, ${ }^{3}$ Department of Biophysics, \\ University of Michigan, Ann Arbor, MI, United States
}

OPEN ACCESS

Edited by:

Axel Mogk,

Heidelberg University, Germany

Reviewed by:

Hans-Georg Koch,

University of Freiburg, Germany

Damon Huber,

University of Birmingham,

United Kingdom

${ }^{*}$ Correspondence:

Changhan Lee

leec@ajou.ac.kr

${ }^{\dagger}$ These authors have contributed equally to this work

Specialty section:

This article was submitted to

Protein Folding, Misfolding and Degradation,

a section of the journal

Frontiers in Molecular Biosciences

Received: 10 March 2021

Accepted: 19 April 2021

Published: 11 May 2021

Citation:

Kim H, Wu K and Lee C (2021) Stress-Responsive Periplasmic

Chaperones in Bacteria.

Front. Mol. Biosci. 8:678697. doi: 10.3389/fmolb.2021.678697
Periplasmic proteins are involved in a wide range of bacterial functions, including motility, biofilm formation, sensing environmental cues, and small-molecule transport. In addition, a wide range of outer membrane proteins and proteins that are secreted into the media must travel through the periplasm to reach their final destinations. Since the porous outer membrane allows for the free diffusion of small molecules, periplasmic proteins and those that travel through this compartment are more vulnerable to external environmental changes, including those that result in protein unfolding, than cytoplasmic proteins are. To enable bacterial survival under various stress conditions, a robust protein quality control system is required in the periplasm. In this review, we focus on several periplasmic chaperones that are stress responsive, including Spy, which responds to envelope-stress, DegP, which responds to temperature to modulate chaperone/protease activity, HdeA and HdeB, which respond to acid stress, and UgpB, which functions as a bile-responsive chaperone.

Keywords: periplasmic chaperone, Spy, DegP, HdeA, HdeB, UgpB

\section{INTRODUCTION}

Proteins are involved in various cellular pathways, such as replication of DNA, gene regulation and metabolism, in all living organisms. Therefore, the protein quality control in bacteria is directly associated with bacterial survival in various natural environments and host niches. Bacterial protein synthesis and homeostasis are targeted by natural and man-made antimicrobial substances (McCoy et al., 2011; Klebanoff et al., 2013; Bednarska et al., 2016). In order to cope with these damaging conditions, bacteria need to immediately sense environmental changes and react rapidly and appropriately. Some types of stressors, such as temperature change, desiccation, and acidity, have negative impacts on protein stability.

Molecular chaperones are key players of protein folding homeostasis (proteostasis). A sophisticated network of chaperones exists in every organism, and these chaperones fulfill various roles, including preventing protein aggregation, disaggregating aggregated proteins, and aiding in protein folding (Tyedmers et al., 2010; Hartl et al., 2011; Valastyan and Lindquist, 2014). Bacterial chaperone systems have been extensively studied in Escherichia coli. In the cytoplasm of E. coli, the DnaK (Hsp70)/DnaJ (Hsp40)/GrpE and GroEL/GroES chaperone systems function as foldases in an ATP-dependent manner, and they aid in the folding of newly translated proteins and unfolded proteins (Saibil, 2013). Under stress conditions such as heat shock, the small heat shock proteins (sHsps) IbpA and IbpB act as holdases that serve as transient reservoirs for the prevention of irreversible aggregation and the facilitation of aggregated-protein resolubilization 
by disaggregating chaperones, which occurs in an ATPindependent manner (Mogk et al., 2019). Subsequently, DnaK/DnaJ/GrpE and the ClpB (Hsp100) disaggregase cooperatively interact with and unfold protein aggregates (Mogk et al., 2018).

Gram negative bacteria possess a periplasmic space that is located between the inner cytoplasmic membrane and the bacterial outer membrane. A number of proteins with diverse function are present in the periplasm, for example, degradative enzymes such as phosphatases, proteases, and endonucleases; and antibiotic detoxifying enzymes such as $\beta$-lactamases, alkyl sulfodehydrases, and aminoglycoside phosphorylating enzymes; binding proteins for amino acids, sugars and vitamins (Neu and Heppel, 1965; Han et al., 2014). A wide range of outer membrane proteins and proteins that are secreted into the external cellular region must pass through the periplasm (Szewczyk and Collet, 2016). SecYEG complex mediates the transports of the most precursor proteins across the inner membrane (Van Den Berg et al., 2004). The precursor protein is unstructured and its signal sequence is cleaved during the translocation (Van Den Berg et al., 2004). After translocation, proteins are on the different folding pathways, and Skp and SurA are major periplasmic chaperones which can bind to the variety of unfolded outer membrane proteins during the transit through the periplasm, preventing their aggregation and facilitating their insertion into the membrane (Stull et al., 2018a; Figure 1). The outer membrane protein assembly factor BamA facilitates folding of the chaperone-bound outer membrane proteins into lipid bilayers (Bennion et al., 2010; Patel and Kleinschmidt, 2013). Homotrimeric Skp is a functional form as a chaperone and has a "jellyfish"-like structure with three $\alpha$-helical flexible tentacles which provide a hydrophobic cavity inside to accommodate a client protein (Schiffrin et al., 2016). SurA has three domains consisting of core domain and two peptidylprolyl isomerase domains, and recent study has shown that a client protein can bind to a cradle formed between the SurA domains (Calabrese et al., 2020).

Periplasmic proteins are more exposed to external environmental stresses than cytoplasmic proteins are, as porins in the outer membrane allows for the free diffusion of small molecules below $\sim 600$ Da (Nikaido, 2003; Figure 1). Thus, periplasmic proteins must be able to cope with extreme environmental changes. For example, as enteric bacteria pass through the host digestive system, the bacteria encounter various host-defense barriers that target protein stability, including gastric acid in the stomach and bile in the duodenum, both of which denature proteins (Dill and Shortle, 1991; Cremers et al., 2014). Therefore, various periplasmic chaperones are transcriptionally and/or post-translationally regulated under stress conditions. In this review, we discuss how these stressresponsive periplasmic chaperones respond to environmental stresses and modulate their activity, but we do not discuss the complete set of stress-responsive periplasmic chaperones, as they have recently been comprehensively reviewed (Stull et al., 2018a). Instead, we have chosen to focus particularly on the periplasmic chaperones which are regulated at the post-translation level by environmental stresses such as the temperature-responsive chaperone/protease DegP; the acid-responsive chaperone, HdeA and $\mathrm{HdeB}$; and the bile-responsive chaperone, UgpB. We also discuss Spy which is nearly not expressed under non-stress conditions, but it is massively induced upon exposure to the envelope stress.

\section{DISTINCT NATURE IN THE PERIPLASM FOR CHAPERONES COMPARED TO THE CYTOPLASM}

The folding environment in the periplasmic space is different from that in the cytoplasm. For example, ATP is absent in the periplasm. Many cytoplasmic chaperones utilize ATP to modulate chaperone activity (Hartl et al., 2011). Since ATP is absent in the periplasm, periplasmic chaperones require a different means of modulating their activity. Another difference between the periplasm and the cytoplasm is the thiol-disulfide redox state. In the periplasm, proteins have high potential for forming disulfide bond, which is not simply due to the presence of oxygen. The oxidizing environment directly results from the presence of the disulfide bond (Dsb) family of enzymes in the periplasm. Dsb proteins catalyze disulfide bond formation and isomerization (Bardwell, 1994; Ito and Inaba, 2008). Deleting the genes encoding the Dsb proteins dramatically reduces the abundance of a range of proteins that normally contain disulfides due to the effect of disulfides on protein folding and stability (Bardwell et al., 1991).

\section{STRESS-RESPONSIVE CHAPERONES IN PERIPLASM}

The bacterial envelope and periplasm are at the front lines of external stress. Because of this, bacteria have several pathways to sense and respond to these stresses. In E. coli, five response pathways, designated BaeSR two component system, CpxARtwo component system, phase shock protein (Psp) system, regulator of capsular synthesis (Rcs) system, and sigma factor $\sigma^{E}$, are responsible for responding to envelope and periplasmic stresses (Bury-Mone et al., 2009). Periplasmic chaperones are regulated by these stress-responsive pathways. $\sigma^{E}$ responds to heat, membrane, and periplasmic stresses, including those induced by alcohol species and detergents (Ades et al., 2003). The Skp and SurA chaperones are regulated by $\sigma^{E}$, as is the protease/chaperone DegP, the prolyl isomerase FkpA, and the disulfide oxidoreductase DsbC (Rhodius et al., 2006; Sklar et al., 2007; Bury-Mone et al., 2009; Stull et al., 2018a). DegP and FkpA are also regulated by the Cpx pathway (Bury-Mone et al., 2009). The envelope-stress responsive chaperone Spy is induced by the Bae, Cpx, and Rcs pathways (Bury-Mone et al., 2009; Quan et al., 2011). The periplasmic chaperones OsmY and Ivy are under the control of the Rcs pathway (Bury-Mone et al., 2009; Lennon et al., 2015). In addition to being transcriptionally regulated, periplasmic chaperones, including $\mathrm{HdeA}, \mathrm{HdeB}$ and $\mathrm{UgpB}$, are also regulated at the post-translational level (Foit et al., 2013; Lee et al., 2020). Thus, in summary, the vast majority of periplasmic 


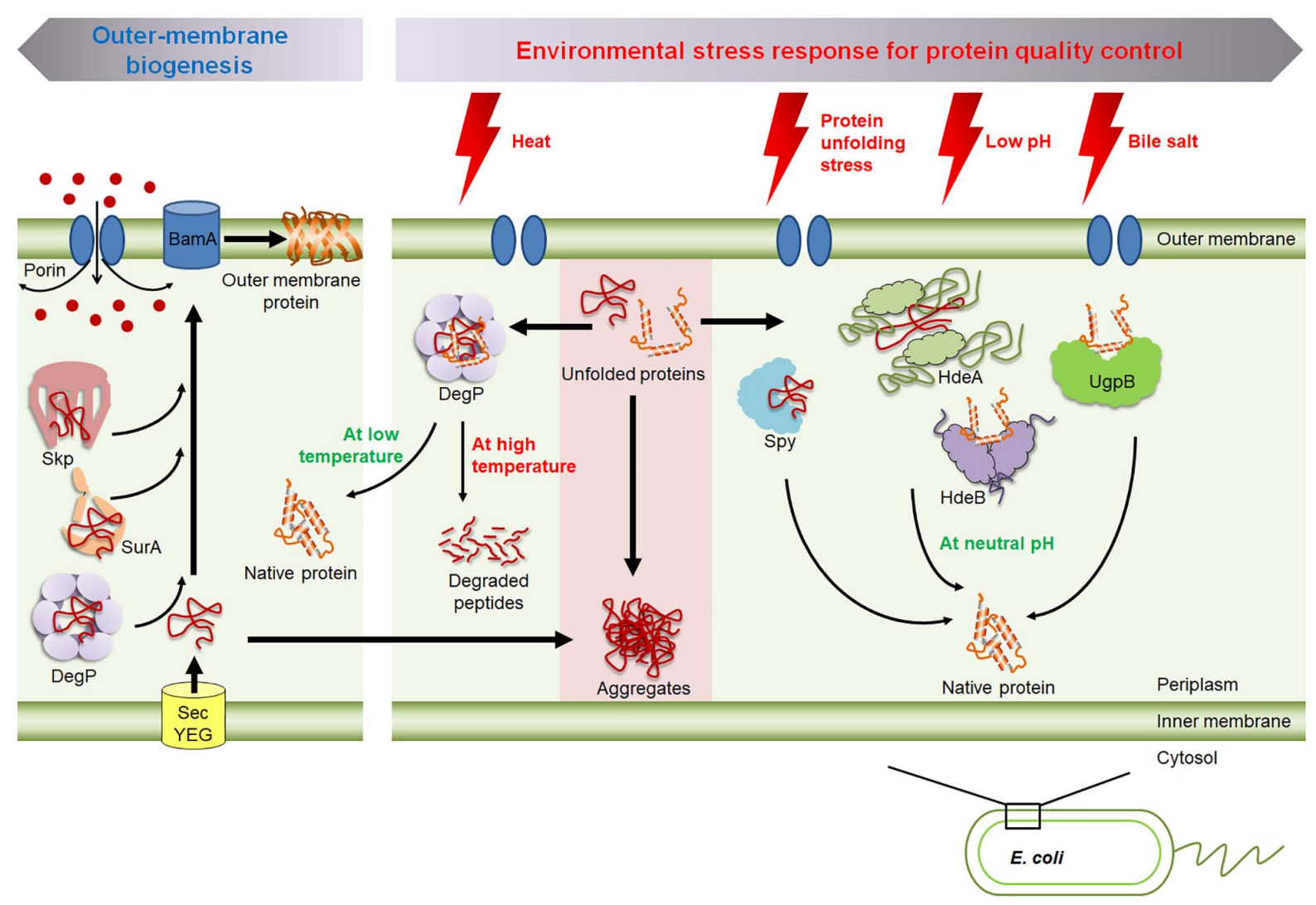

FIGURE 1 | An overview of the molecular chaperones in the periplasm of E. coli. Skp, SurA, and DegP are involved in the biogenesis of outer membrane proteins; i.e., preventing their aggregation and facilitating their insertion into the membrane. The shift of temperature modulates DegP's chaperone and protease activity. HdeA and HdeB prevent acid-induced protein aggregation. Spy and UgpB respond to envelope stress and bile stress, respectively.

chaperones are under some mode of stress control, a fact that has long been known to be true for chaperones present in other compartments, particularly the cytoplasm (Richter et al., 2010).

\section{THE ENVELOPE-STRESS RESPONSIVE CHAPERONE, Spy}

Spy (Spheroplast Protein Y) was initially characterized as a protein whose expression is very strongly increased by spheroplast formation, hence its name (Hagenmaier et al., 1997). Spy is very weakly expressed in unstressed cells, but it is massively induced by spheroplasting, a process that involves disrupting the outer bacterial envelope using treatments such as lysozyme and EDTA (Hagenmaier et al., 1997). That Spy functions as a chaperone was discovered by employing a genetic selection system that uses a protein-folding sensor linking protein folding to antibiotic resistance (Quan et al., 2011). The protein folding sensor is a tripartite fusions between two proteins, in which an unstable test protein is inserted into the middle of a selectable antibiotic marker (Foit et al., 2009). The protein-folding sensors used in the discovery of Spy, UgpB and other proteins exhibiting chaperone activity (Foit et al., 2009; Lennon et al., 2015; Lee et al., 2020). For the selection system used to discover Spy, an unstable variant of immunity protein $7(\operatorname{Im} 7)$ was inserted between two halves of $\beta$-lactamase, which confers penicillin resistance (Quan et al., 2011). This makes antibiotic resistance dependent on the folding of the unstable test protein. It was found that overexpression of Spy acts to stabilize the Im7-fused protein-folding sensor and consequently confers high levels of antibiotic resistance to E. coli (Quan et al., 2011). The mechanism underlying Spy's chaperone function has subsequently been very well characterized (Quan et al., 2011; Horowitz et al., 2016; Koldewey et al., 2016; Stull et al., 2016; Wu et al., 2019; Mitra et al., 2021).

Spy is a small protein $(16 \mathrm{kDa})$ which forms a stable dimer in solution (Quan et al., 2011). Each Spy monomer contains four $\alpha$-helices. The dimeric Spy forms a cradle-like structure through an antiparallel coiled-coil interaction. The concave surface of Spy is dominated by positive charges with two hydrophobic patches located in the bottom of cradle (Kwon et al., 2010; Quan et al., 2011). Studies have shown that Spy used almost the entire interior of cradle to rapidly recognize its client proteins, and thereby effectively preventing protein aggregation under stress conditions (Quan et al., 2011; Koldewey et al., 2016).

The expression of Spy is tightly repressed under non-stress conditions but is strongly induced by spheroplasting treatments (Hagenmaier et al., 1997) and the protein denaturants butanol, 
ethanol, and tannin (Figure 2A; Quan et al., 2011). Spy is so strongly induced after tannin and butanol treatments that it can comprise up to $25 \%$ of the total periplasmic protein content (Quan et al., 2011). Spy expression is controlled by the CpxAR and BaeSR two-component signal transduction systems, which respond to protein-unfolding stress in the cellular envelope (Raivio et al., 2000; Raffa and Raivio, 2002; Bury-Mone et al., 2009). Constitutive baeSR mutants greatly overproduce the Spy protein (Quan et al., 2011). This rapid and massive production of Spy under stress is clearly an important way to modulate the chaperone function of Spy in the periplasm. Spy deletion mutants are sensitive to tannin and zinc treatments (Quan et al., 2011; Wang and Fierke, 2013). In a recent study, Spy was isolated as suppressor in ely $C$ mutants at low temperature $\left(21^{\circ} \mathrm{C}\right)$ (Kouidmi et al., 2018). ElyC is a factor involved in peptidoglycan biosynthesis at low temperatures (Paradis-Bleau et al., 2014), The deletion of elyC gene increases the amount of cellular protein aggregates, and the overexpression of Spy can significantly reduce the amount of protein aggregates and completely suppress the defect in peptidoglycan biosynthesis, suggesting that the absence of ElyC causes protein folding problem in the periplasm (Kouidmi et al., 2018). Spy homologs are widely present in enterobacteria and proteobacteria, and in some cyanobacteria (Quan et al., 2011).

The mechanism through which Spy acts on its client proteins has been extensively investigated, particularly with the model substrate, Im7 (Figure 2A). The prevailing paradigm has been that hydrophobic interactions are the major driving forces leading chaperones to recognize its clients (Kim et al., 2013). However, it has recently been shown that electrostatic interactions also play an important role in chaperone actions, particularly for Spy (Coyle et al., 1997; Koldewey et al., 2016, 2017; Lee et al., 2018). These results are consistent with the recent observation that Super Spy variants with enhanced chaperone activity not only exhibit increased hydrophobicity but also an increase in electrostatic interactions (He et al., 2020). Electrostatic interactions are effective over much longer distances than hydrophobic interactions (Selzer and Schreiber, 1999; Schreiber et al., 2009). The highly basic nature of Spy's substrate-binding surface drives charge-charge interactions with client proteins (Koldewey et al., 2016). These long-range electrostatic interactions between the positively charged Spy and its negatively charged client proteins increase the association rate between these two entities, allowing Spy to rapidly bind to unfolded, aggregation-prone substrates, thereby preventing their aggregation (Koldewey et al., 2016). After the substrate has been recognized via long-range electrostatic interactions, short-range hydrophobic interactions occur between Spy's central cradle region and its unfolded substrates, resulting in the stabilization of the Spy-substrate complex (Koldewey et al., 2016).

Following studies showed that two folding model substrates, Im7 and Fyn SH3, are allowed to fold into their native states while they are bound to Spy (Stull et al., 2016; Wu et al., 2019). Protein folding while bound to chaperone Spy is apparently dependent on the affinity between chaperone and its client (Wu et al., 2019). The more tightly Spy binds its clients, the more it slows the folding of bound clients. Evolution seems to achieve this delicate chaperone action by fine-tuning Spy's binding affinity to its clients (Wu et al., 2019). By having too strong binding affinity, Spy could unfold its client proteins and cause toxic effects on cells; while having too weak affinity would sacrifice its chaperone activity (Wu et al., 2019). Thus, having a modest binding affinity might be a better evolutionary solution for chaperone, like Spy, to mediate protein folding before more advanced regulatory mechanisms were developed. Upon substrate folding, the hydrophobic contacts between Spy and its substrates are reduced, increasing the dissociation rate and promoting the substrate release (Koldewey et al., 2016; Stull et al., 2016). A very recent study showed that the chaperone mechanism of Spy could be substrate-dependent (Mitra et al., 2021). In the case of apo-flavodoxin, Spy can rapidly recognize and stabilize a partially unfolded state, and thereby effectively suppressing protein aggregation during stresses. On the other hand, tight substrate binding eliminates the possibility for apo-flavodoxin to refold to its native state while bound to Spy. This study highlights the importance of substrate-dependent chaperone mechanisms, in which chaperones could have different modes of action for different client proteins (Table 1; Koldewey et al., 2017). Yet, future studies are required to demonstrate how these client proteins which are tightly bound to Spy are subsequently released to the solution as the stresses are removed.

\section{THE TEMPERATURE-RESPONSIVE PROTEASE/CHAPERONE, DegP}

DegP (also called HtrA or protease Do) is known to play a central role in the protein quality control network in the periplasm through its dual function; i.e., its protease activity for the removal of misfolded or damaged proteins and its chaperone activity. DegP was first identified as a protease essential for growth of E. coli at high temperature (Lipinska et al., 1989; Strauch et al., 1989). DegP is highly conserved in most Gram-negative bacteria (Lipinska et al., 1990; Pallen and Wren, 1997). DegP deletion mutant is lethal at high temperature $\left(42^{\circ} \mathrm{C}\right.$ ) (Skorko-Glonek et al., 1995). Of note, overexpression of protease-deficient forms of DegP can sufficiently suppress the lethal phenotype, suggesting that DegP protease activity is not mandatory for heat tolerance (Misra et al., 2000; CastilloKeller and Misra, 2003). DegP is part of a large serine proteases-related family which is found in most organisms (Chang, 2016) and is upregulated by the $\sigma \mathrm{E}$ and $\mathrm{Cpx}$ pathway under heat, membrane, and periplasmic stresses (Danese et al., 1995; Alba and Gross, 2004). DegP is also associated with thermal, osmotic and oxidative stress tolerance (Pallen and Wren, 1997; Gunasekera et al., 2008). Moreover, degP deletion mutants of several pathogenic bacteria are attenuated, suggesting that DegP might be involved in bacterial virulence (Pallen and Wren, 1997).

The mature DegP protein is composed of three domains, the chymotrypsin-related protease domain which contains an active site His-Asp-Ser motif at the $\mathrm{N}$ terminus and the two PDZ domains (PDZ1 and PDZ2) at the $\mathrm{C}$ terminus which play important roles in substrate recognition as well as in the transformation of DegP to large cage-like structures 
A
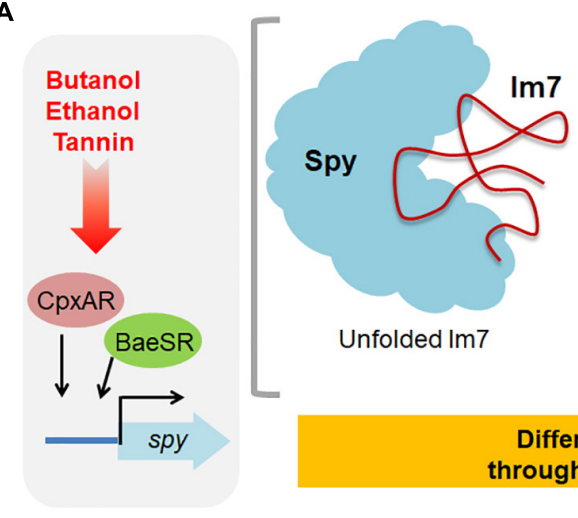

Unfolded $\operatorname{Im} 7$
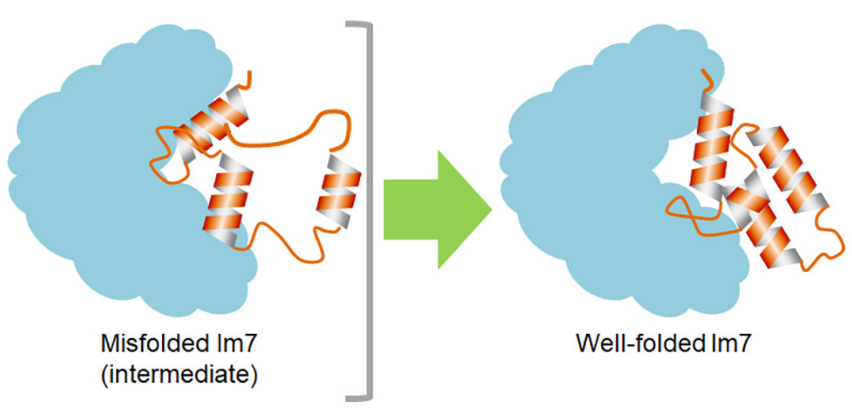

Well-folded Im7

Different binding affinity between Spy and Im7 through hydrophobic and electrostatic interactions

\section{Protein Folding while Spy bound}

B

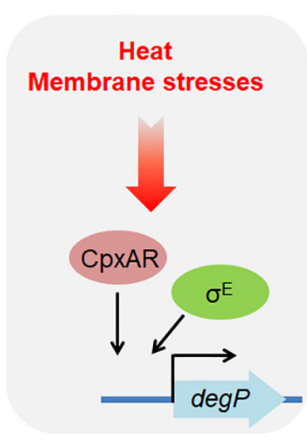

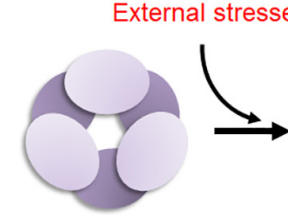

$\operatorname{DegP}_{6}$

Resting state

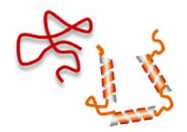

Misfolded / unfolded protein

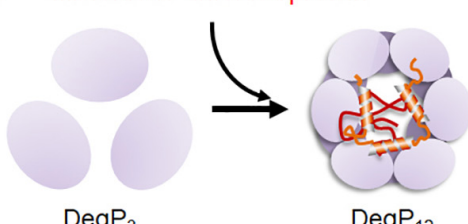

$\operatorname{DegP}_{12}$

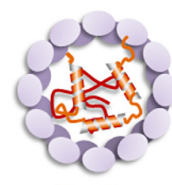

$\operatorname{DegP}_{24}$

Protease activity / Chaperone activity
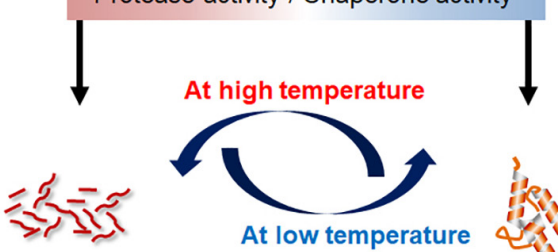

Degraded peptides
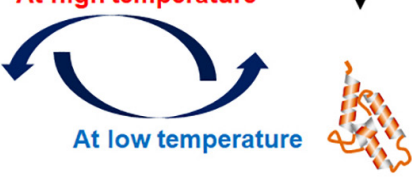

Native protein

FIGURE 2 | An overview of the molecular mechanisms of Spy and DegP. (A) The envelope-stress conditions occurring under butanol, ethanol, and tannin exposure induce the production of the chaperone Spy, which binds to misfolded or unfolded substrates by electrostatic and hydrophobic interactions. Spy prevents further aggregation of the substrate and enables proper folding of the substrate while it is bound to Spy. (B) DegP exhibits both the chaperone and protease activity. The hexameric form of DegP is a resting state. The exposure to external stresses, the hexameric DegP presumably dissociated to trimers, which are a basic building unit for the formation of large cage-like structures. The 12- and 24-mer of cage-like DegP complexes can encapsulate bound substrates for its chaperone and protease activity. The stress-induced conformation changes of DegP and the folding state of the bound substrates are thought to be involved in determining the fate of DegP as a chaperone or protease.

(Ortega et al., 2009). Purified DegP present as a hexamer in solution and is composed of a dimer of two trimers, which is a resting state of DegP (Figure 2B; Krojer et al., 2002; Clausen et al., 2011). The hexameric DegP can be activated through the rearrangement into 12-mers/24-mers of cage-like structure, which can encapsulate substrate proteins (Krojer et al., 2002, 2008; Jiang et al., 2008; Kim et al., 2011). The trimeric DegP is a building unit for the different large cage-like structure and thus it is assumed that DegP undergoes a large structural changes from the hexameric resting state through a trimeric state to the higher oligomeric state (Li et al., 2014; Thompson et al., 2014). The presence of the substrate triggers the reorganization of hexameric DegP into the large cage-like structure (Jiang et al., 2008; Krojer et al., 2008).

Of note, at low temperature (below $28^{\circ} \mathrm{C}$ ), the protease activity drops and DegP mostly function as a chaperone, suggesting that DegP switches from chaperone to proteolytic activity as a function of temperature (Spiess et al., 1999). However, 
TABLE 1 | Various chaperone actions and mechanisms of Spy.

\begin{tabular}{|c|c|c|}
\hline In vitro client & Spy's action & References \\
\hline Malate dehydrogenase (MDH) & Suppress protein aggregation during stresses & Quan et al., 2011 \\
\hline Aldolase & Suppress protein aggregation during stresses & Quan et al., 2011 \\
\hline DsbB & Suppress protein aggregation during stresses & Quan et al., 2011 \\
\hline Alkaline phosphatase & Suppress protein aggregation during stresses & Quan et al., 2011 \\
\hline$\alpha$-lactalbumin $(\alpha-L A)$ & Suppress protein aggregation during stresses & He et al., 2020 \\
\hline $\operatorname{lm} 7$ & Allow the client to refold to its native state while bound & Stull et al., 2016 \\
\hline Fyn SH3 & Allow the client to refold to its native state while bound & Wu et al., 2019 \\
\hline Apo-flavodoxin & Inhibit the client to refold to its native state & Mitra et al., 2021 \\
\hline
\end{tabular}

the underlying molecular mechanism by which DegP switches from chaperone to protease upon temperature shift is still not fully understood. One hypothesis that a temperature-induced conformational change occurs in the proteolytic site (Krojer et al., 2002; Ortega et al., 2009). At low temperatures, the proteolytic serine (Ser-210) residue is present in an inactive conformation away from other residues of the catalytic triad, resulting that only chaperone activity is exhibited. However, it has been suggested that the elevation of temperature may induce conformational change in Ser-210 to assemble functional catalytic triad, thus exhibiting protease activity. In terms of folding state of substrates, DegP degrades unfolded outer membrane proteins but stabilizes folded outer membrane proteins (Krojer et al., 2008), suggesting the folding state of bound substrates determines the function of DegP. Temperature undoubtedly affects the folding state of proteins; thus these results partially explain the role of temperature in functional transition of DegP. In recent study, the analysis of the interaction and dynamics of the PDZdomains of DegP by high-resolution NMR spectroscopy reveals that PDZ1-PDZ2 interaction through Met-280 and Tyr-444 residues is crucial for the temperature-dependent regulation in the oligomeric states of DegP (Šulskis et al., 2020).

As a molecular chaperone, DegP enhances the in vitro refolding of the $E$. coli periplasmic $\alpha$-amylase MalS and citrate synthase at low temperature (Spiess et al., 1999). In this study, deletion of the PDZ domains did not affect refolding yields, suggesting that the protease domain itself has chaperone activity (Spiess et al., 1999). DegP has also been shown to prevent aggregation of heat-denatured citrate synthase and lysozyme by acting as a holdase (Skorko-Glonek et al., 2007). DegP is also involved in the biogenesis of outer membrane proteins by protecting them from aggregation and proteolytic degradation during their transport across the periplasm (Krojer et al., 2008). Deletion of $\operatorname{deg} P$ shows a synthetically lethal phenotype with deletion of either a surA or $s k p$, suggesting that DegP plays a role in outer membrane protein biogenesis as SurA and Skp (Sklar et al., 2007).

\section{THE ACID-RESPONSIVE CHAPERONES, HdeA AND HdeB}

Escherichia coli has two acid-responsive periplasmic chaperones, HdeA and HdeB. HdeA and HdeB are very small proteins, 11 and
$12 \mathrm{kDa}$, respectively, and they share $17 \%$ amino acid sequence identity and have similar structures (Wang et al., 2012; Stull et al., 2018a). Both proteins are well-folded $\alpha$-helical dimers at neutral $\mathrm{pH}$ that bury their hydrophobic surfaces in their dimerization regions (Yang et al., 1998). It appears that HdeA functions at low $\mathrm{pH}$ levels ( $\mathrm{pH} 1-3$ ), whereas $\mathrm{HdeB}$ functions under mildly acidic conditions (pH 4-5) (Kern et al., 2007; Malki et al., 2008; Dahl et al., 2015; Ding et al., 2015). The genes encoding the HdeA and HdeB proteins form an operon that is located on a genomic island (termed as an acid fitness island) (Mates et al., 2007). The hdeAB operon was also identified in Shigella flexneri and Brucella abortus (Hong et al., 2012). The transcription of $h d e A B$ is induced by the overproduction of the DNA-binding transcriptional regulator $\mathrm{YdeO}$, which is upregulated by the acidresponsive EvgSA two component system (Masuda and Church, 2003), and the RNA polymerase holoenzyme assembly factor $\mathrm{Crl}$ can also increase $h d e A B$ expression through RpoS (Dudin et al., 2013). HdeA is the 6th most abundant protein in the cell during stationary phase (Link et al., 1997). Thus, bacteria can immediately respond to acid stress.

Under acidic conditions, the acid stress causes protein misfolding by disrupting the hydrogen bonds and salt bridges required for protein folding. Because of the porous nature of the outer membranes of Gram-negative bacteria, changes in the $\mathrm{pH}$ of the surrounding environment cause a corresponding rapid change in the $\mathrm{pH}$ of the periplasmic space. It was recently shown that a large drop in extracellular $\mathrm{pH}$ triggers a surge in periplasmic chloride ions to a concentration that can exceed 0.6 M due to the Donnan effect (Stull et al., 2018b). In the low $\mathrm{pH}$, the increase of chloride anions accelerates protein aggregation in the periplasm, because it neutralizes the positive charges of the protein, minimizing the force of the electrostatic repulsion between unfolded proteins, that would prevent protein aggregation (Stull et al., 2018b). When bacteria transit through the acidic environment of the host stomach, protecting their periplasmic proteins from acid stress is necessary for bacterial survival. Consistently, an $h d e A$ mutant showed reduced survival after exposure to low $\mathrm{pH}$ conditions (Waterman and Small, 1996; Gajiwala and Burley, 2000; Mates et al., 2007).

To function as chaperones, HdeA and $\mathrm{HdeB}$ appear to utilize changes in external $\mathrm{pH}$ to trigger chaperone activation, inactivation, and substrate-protein refolding (Figure 3A). Upon exposure to acidic conditions, $\mathrm{HdeA}$ and $\mathrm{HdeB}$ partially unfold, resulting in the activation of their chaperone activities 
(Foit et al., 2013; Dahl et al., 2015; Yu et al., 2019). HdeA undergoes a dramatic conformational change from a well-folded chaperone-inactive dimer to a partially disordered, chaperoneactive monomer (Yang et al., 1998; Foit et al., 2013; Salmon et al., 2018). The hydrophobic surfaces involved in the dimeric interaction surface become exposed and serve as a substratebinding site (Yu et al., 2019). Recent NMR studies have proposed that HdeA contains two hydrophobic patches (site I: 49-55AA, site II: 28-35AA) that are involved in client binding and three acid-sensitive regions, A, B, and C (A: 46-51 AA; B: 34-40 AA; and C: 24-29 AA), that act as structural triggers that regulate the exposure of the two client-binding sites (Yu et al., 2019). Thus, multiple steps occur in the HdeA activation mechanism during the transition to a low $\mathrm{pH}$ ( $\mathrm{Yu}$ et al., 2019). Upon returning to neutral $\mathrm{pH}, \mathrm{HdeA}$-substrate complexes spontaneously dissociate, and the substrates are released in a folding-competent state (Tapley et al., 2010). Thus, the cycle of chaperone action for HdeA is intricately modulated by host-induced $\mathrm{pH}$ changes.

In HdeA, client-binding site $\mathrm{I}$ is located in a relatively peripheral region of the HdeA dimer structure, where it is shielded by the N-terminal segment of the other HdeA monomer (Figure 3A; Yu et al., 2019). The acidic residues in acidsensitive region A (Glu-46, Asp-47, and Asp-51 with pKa values of $4.07,4.14$, and 3.83 , respectively) are deprotonated under neutral and near-neutral conditions $(\mathrm{pH}>4)$, ensuring an electrostatic interaction with the $\mathrm{N}$-terminal region of $\mathrm{HdeA}$ (Garrison and Crowhurst, 2014). At pH values below 4, the protonation of these residues disrupts the electrostatic interaction with the N-terminal region, exposing client-binding site I (Yu et al., 2019). The regulatory role of the $\mathrm{N}$-terminal region is supported by the observation that an HdeA variant containing a nine residue $\mathrm{N}$-terminal deletion shows enhanced interaction with its client proteins (Gajiwala and Burley, 2000) and also exhibits partial anti-aggregation activity at $\mathrm{pH}$ 4.0, whereas wild-type HdeA is inactive at this $\mathrm{pH}$ (Dahl et al., 2015; Yu et al., 2019). A constitutively active mutation in HdeA (D20A/D51A) may also affect the regulatory function of the $\mathrm{N}$-terminal region (Foit et al., 2013). Client-binding site II is tightly packed in the structural core of the HdeA dimer and can only be exposed after extensive disruption of the dimeric interface. At $\mathrm{pH}$ values above 4 , the two acid-sensitive regions $\mathrm{B}$ and $\mathrm{C}$ stabilize the dimer interface via inter- and intrasubunit contacts ( $\mathrm{Yu}$ et al., 2019). As the pH decreases to values below 4, local structural destabilization disrupts the interactions between acid-sensitive regions $\mathrm{B}$ and $\mathrm{C}$, partially exposing client-binding site II (Yu et al., 2019). Further decreases in $\mathrm{pH}$ to values below 2 lead to a complete collapse of the protein structure of HdeA, resulting in a fully active chaperone (Yu et al., 2019).

The periplasmic chaperones SurA and DegP have been implicated as HdeA substrates under low-pH conditions (Zhang et al., 2011), and HdeA suppresses the acid-induced aggregation of SurA in vitro (Zhang et al., 2011). In addition, SurA or DegP assists HdeA in refolding acid-denatured alkaline phosphatase in vitro, suggesting that HdeA protects chaperones, such as SurA and DegP, and subsequently enables these chaperones to participate in the refolding of substrate proteins that are dissociated from HdeA following the transition to neutral $\mathrm{pH}$ (Zhang et al., 2011). Fibrillation of HdeA at pH 2 has been observed in a recent study, and these fibrils can be resolubilized following a shift to $\mathrm{pH} 7$ (Miyawaki et al., 2019). This unusual reversibility of fibrillation for HdeA suggests this is another $\mathrm{pH}$-dependent regulatory mechanism for HdeA.

The functional mechanism of HdeB is less well understood than that of HdeA. In contrast to HdeA, HdeB appears to function as a dimer in preventing acid-induced protein aggregation and facilitating refolding upon neutralization (Dahl et al., 2015). HdeB exhibits optimal chaperone activity at $\mathrm{pH}$ 4 in vitro (Dahl et al., 2015). HdeB has a well-folded dimeric structure at neutral $\mathrm{pH}$, but it starts to undergo partial unfolding near $\mathrm{pH} 3$ and reaches an overall unfolded state at $\mathrm{pH} 2-1.5$ (Dahl et al., 2015; Ding et al., 2015). HdeB does not show significant chaperone activity at $\mathrm{pH} 2$ (Dahl et al., 2015), suggesting that the activation of the $\mathrm{HdeB}$ chaperone function is linked to $\mathrm{pH}$ dependent conformational changes rather than monomerization (Ding et al., 2015).

A protein sequence alignment of the HdeA and HdeB homologs revealed that the $\mathrm{N}$-terminal nine residues present in HdeA are lacking in the N-terminus of $\mathrm{HdeB}$ ( $\mathrm{Yu}$ et al., 2019). Since these residues are involved in protecting the clientbinding site on HdeA, the client-binding site in $\mathrm{HdeB}$ is thus presumably constitutively exposed, allowing $\mathrm{HdeB}$ to interact with its client proteins under non-acidic conditions without the need for protein unfolding (Yu et al., 2019). Consistent with this hypothesis, $\mathrm{HdeB}$ prevents the aggregation of some substrates (like lactate dehydrogenase) at $\mathrm{pH} 7.5$ in vitro (Lennon et al., 2015). HdeB copurifies with HdeA (Arnqvist et al., 1994), but $\mathrm{HdeB}$ and $\mathrm{HdeA}$ do not appear to heterodimerize in vitro (Kern et al., 2007; Dahl et al., 2015).

\section{THE BILE-RESPONSIVE CHAPERONE, UgpB}

UgpB is a periplasmic substrate-binding protein and a component of the uptake of glycerol phosphate system (Ugp system), which is also known as the glycerol-3-phosphate (G3P) ATP-dependent binding cassette transporter. It is conserved in various Gram-negative bacteria, including E. coli (Argast and Boos, 1979; Wuttge et al., 2012). Purified UgpB binds to G3P and glycerophosphocholine in vitro (Wuttge et al., 2012). These bound substrates are transferred to the inner membrane associated with the Ugp complex and then transported into the cytosol through the hydrolysis of ATP (Wuttge et al., 2012). Transported G3P can be utilized as a carbon or phosphate source (Wanner, 1996). We have recently shown that UgpB also functions as a bile-responsive chaperone (Lee et al., 2020). Bile is an amphipathic compound that assists mammals in the absorption of lipids (Heaton, 1969; Gunn, 2000; Urdaneta and Casadesus, 2017). Bile also exhibits potent antimicrobial activity mediated by its ability to disrupt cell membranes, cause DNA damage, and, importantly in reference to its chaperone activity, cause protein unfolding and aggregation (Prieto et al., 2004; Merritt and Donaldson, 2009; Cremers et al., 2014; 


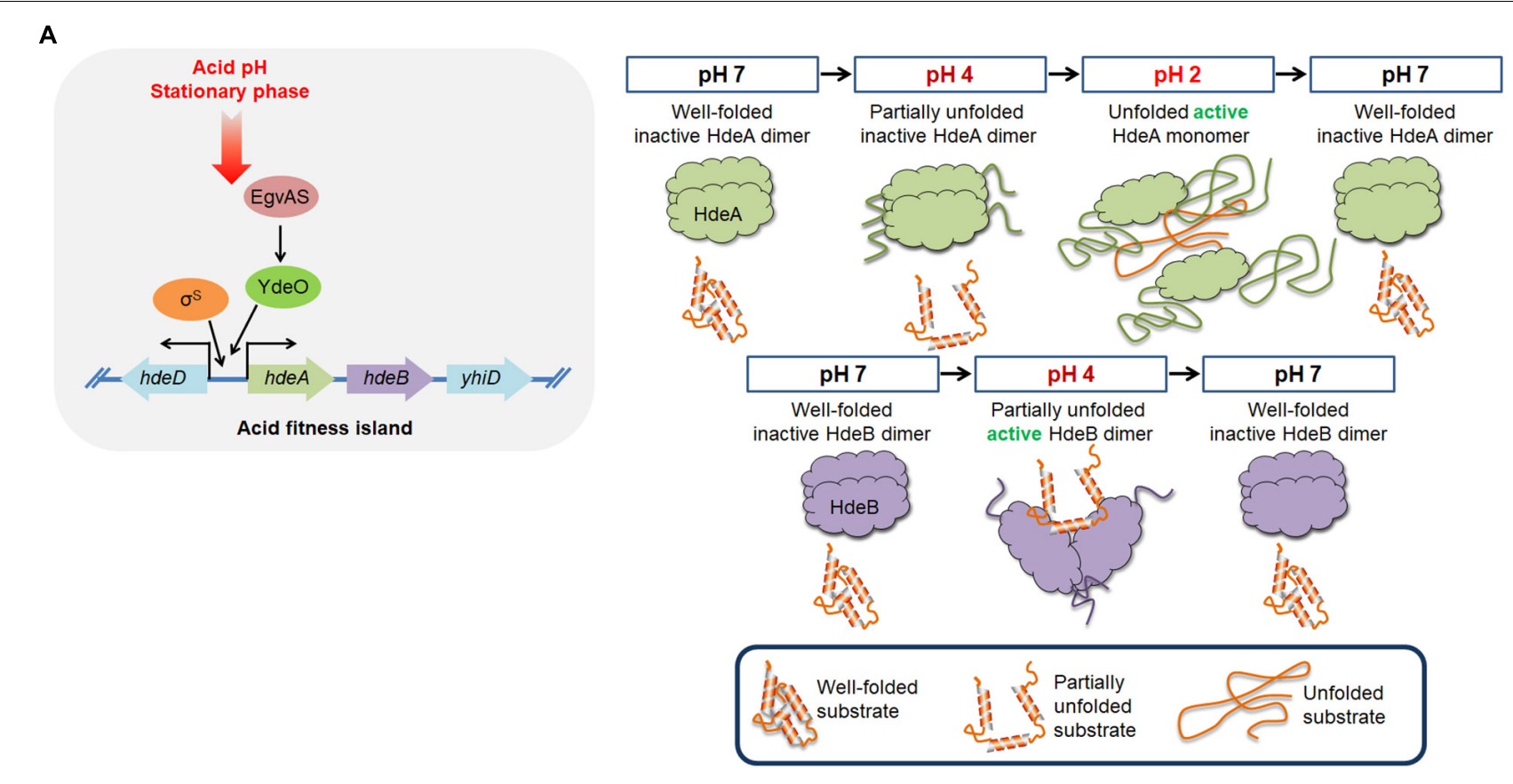

B

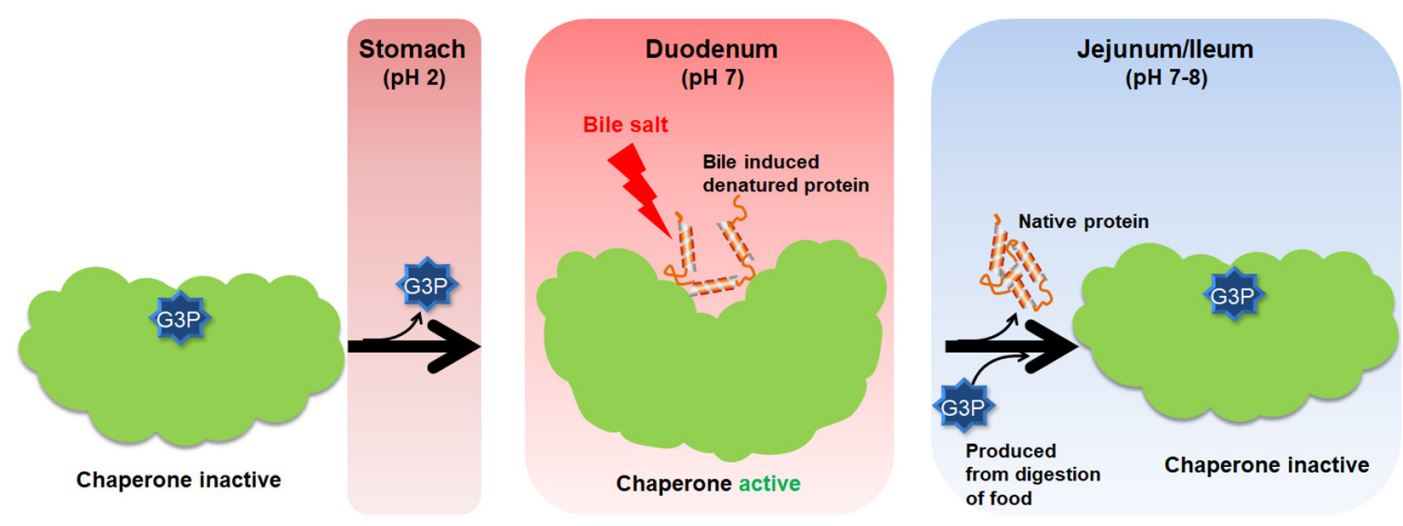

FIGURE 3 | An overview of the molecular mechanism of HdeA, HdeB, and UgpB. (A) Acidic pH levels and stationary phase can induce the expression of HdeA and $\mathrm{HdeB}$, which act to protect a broad range of periplasmic proteins from acid-induced aggregation. At neutral pH, HdeA exists as a well-folded homodimer in an inactive state. At pH 2, the unfolded monomer form of HdeA can bind to the hydrophobic surfaces of denatured substrates and protect them from aggregation. HdeB also protects proteins from acid-induced aggregation. In contrast to HdeA, HdeB exhibits chaperone activity at pH 4 in a dimeric, partially unfolded form. (B) The E. coli periplasmic G3P-binding protein UgpB exhibits chaperone activity against bile salts. The chaperone activity of UgpB is evident only when G3P is stripped off of UgpB. Bacterial cells must pass through the acidic stomach and the bile-rich duodenum to reach the lower intestine where they colonize. Acidic pH levels in the stomach can unfold UgpB, resulting in the dissociation of G3P. Consequently, UgpB exerts chaperone activity to prevent bile salt-induced protein aggregation in the duodenum. Release of G3P exposes the core cleft region of UgpB, which functions as a chaperone active surface. An increase in the G3P concentration in the jejunum and ileum resulting from the digestion of food triggers a functional transition of UgpB from molecular chaperone to G3P transporter.

Urdaneta and Casadesus, 2017). Bile enters the bacterial cytosol through a flip-flop mechanism (Cabral et al., 1987), and its entry leads to the induction of various chaperones, including Hsp33, DnaK, and GroEL (Flahaut et al., 1996; Bernstein et al., 1999; Leverrier et al., 2003; Ruiz et al., 2013; Cremers et al., 2014). The bacterial periplasm is presumably more highly exposed to bile than the cytosol is, owing to the porous nature of the outer periplasmic membrane, but, surprisingly, very little is known about how periplasmic proteins are protected against bile.
High-throughput transposon sequencing (Tn-Seq), in combination with a periplasmic protein-folding sensor, allowed us to establish that UgpB has chaperone activity (Lee et al., 2020). Tn-Seq allows one to compare the transposoninsertion frequencies between all genes in the genomes of two populations, one of which has been subject to genetic selection (Van Opijnen et al., 2009; Burby et al., 2017). Gene disruption by transposon insertion may affect the growth rate under the applied selection condition, and consequently 


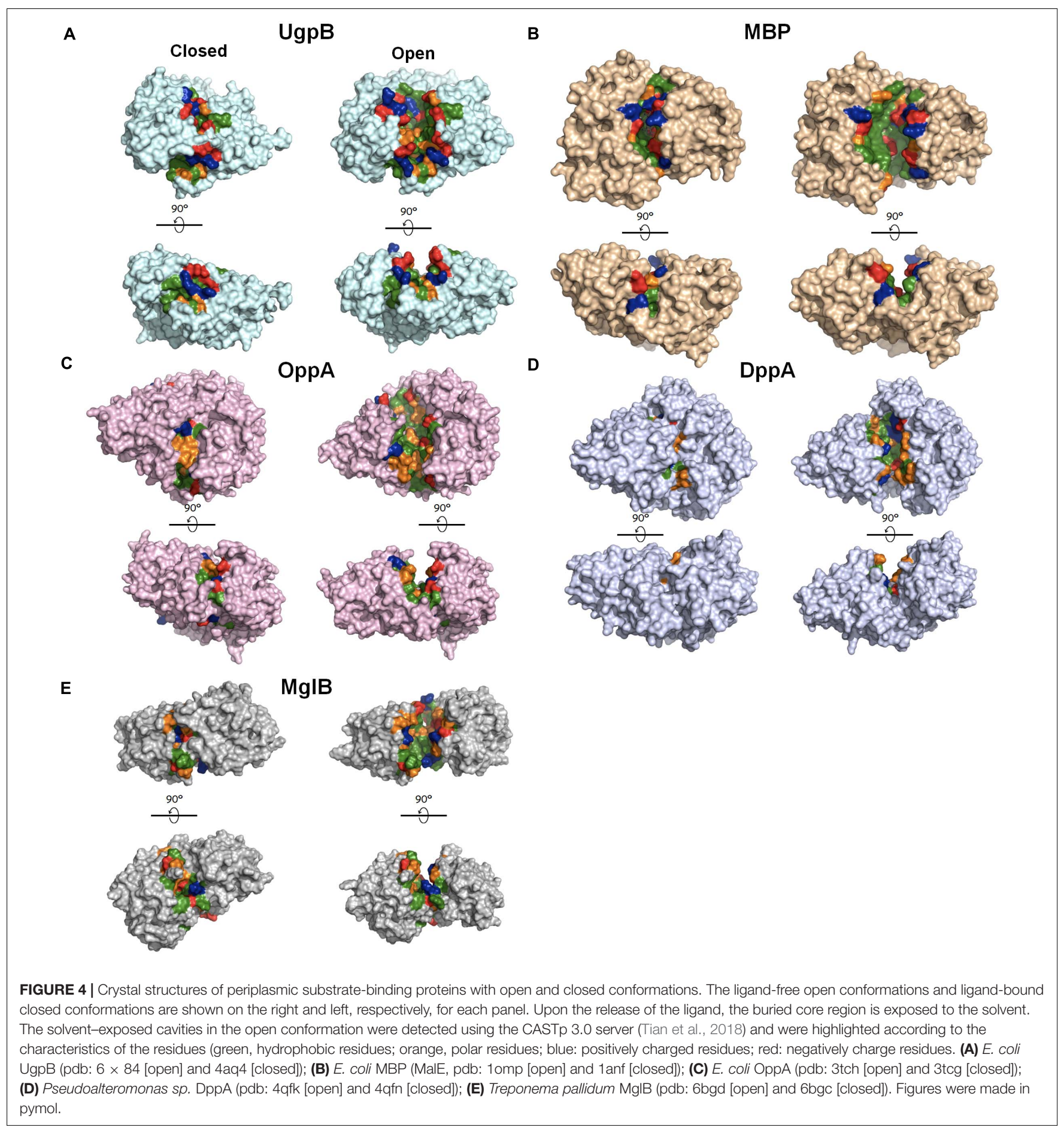

certain genes shows altered transposon insertion frequencies. A periplasmic protein-folding sensor, which links protein stability to antibiotic resistance, provides powerful selection power for Tn-Seq. The unstable $\operatorname{Im} 7$ variant was used as a test protein in the context of the protein-folding sensor (Quan et al., 2011; Lee et al., 2020). The gene encoding Spy was rediscovered using this method (Lee et al., 2020). Another locus that had a highly elevated transposon insertion frequency was the pstSCA operon (Lee et al., 2020). PstSCA encodes an ATP-binding cassette transporter for phosphate uptake, and the disruption of each of these genes alters the expression levels of downstream genes, including $u g p B$ (Gardner et al., 2015). In pst mutants, UgpB becomes the most abundant protein in the periplasm, and overexpression of UgpB acts to stabilize the protein-folding sensor in vivo (Lee et al., 2020). 
Bile induces UgpB expression. Disrupting the $u g p B$ gene confers bile sensitivity (Nichols et al., 2011; Hernandez et al., 2012), and overexpressing UgpB confers bile resistance (Lee et al., 2020). UgpB can prevent bile-induced protein aggregation (Lee et al., 2020). UgpB has, as a structural characteristic of periplasmic substrate-binding proteins, which are two globular domains connected by a hinge where the substrate, in this case G3P binding at the interface between the two domains (Figures 3B, 4; Wuttge et al., 2012). UgpB only exhibits chaperone activity when UgpB is in the G3P-free open state (Lee et al., 2020). Protein structural analysis and mutational targeting of G3Pbinding residues revealed to us that a deep cleft opens up in UgpB when G3P is released (Lee et al., 2020). Consequently, a number of hydrophobic residues in the core cleft region are exposed, and this region then can function as a surface for chaperone activity (Lee et al., 2020). In addition, G3P can compete for the client protein that binds to UgpB, suggesting that UgpB's G3P-binding and chaperone activities are mutually exclusive.

How is the chaperone activity of UgpB modulated in the host? Since G3P binding to UgpB inhibits its chaperone activity, there must be a mechanism to strip G3P from UgpB to prime it as an active chaperone before bacteria reach the duodenum, where bile is secreted. Bacteria have to pass through the stomach before they reach the duodenum. Since low $\mathrm{pH}$ unfolds proteins, including UgpB, any G3P bound to UgpB can be removed through exposure to the low $\mathrm{pH}$ conditions present in the stomach (Figure 3B; Lee et al., 2020). At neutral pH levels, like those present in the duodenum, UgpB is refolded, and it can thus function there as a bile-responsive chaperone (Lee et al., 2020). At subsequent points in the digestive tract, i.e., in the jejunum and ileum, bile is diluted out and efficiently absorbed, decreasing the bile concentration (Heaton, 1969; Weski and Ehrmann, 2012). Digesting food increases the G3P concentration in the jejunum and ileum, and this induces a role reversal in UgpB, in which it regains its activity as a periplasmic G3P-binding protein (Lee et al., 2020).

Diverse periplasmic substrate-binding proteins bind to their specific substrates such as amino acids, peptides, sugars and vitamins, and deliver them to the transport protein in the inner membrane to transport them into the cytoplasm (Ames, 1986). Periplasmic substrate-binding proteins share structural similarities, including two conserved domains linked by a hinge and a substrate-binding surface located at the interface between the two domains (Figure 4; Wuttge et al., 2012). Of note, in addition to UgpB, the chaperone activities of various bacterial periplasmic substrate-binding proteins, such as maltose-binding protein $(\mathrm{MBP})$, galactose-binding protein $(\mathrm{MglB})$, oligopeptidebinding protein (OppA), and dipeptide-binding protein (DppA), have previously been detected (Richarme and Caldas, 1997; Lennon et al., 2015). In addition, periplasmic substrate-binding proteins are very abundant at least under some conditions as UgpB and other chaperones. For example, OppA and DppA are highly induced at the stationary phase (Sangurdekar et al., 2006). MBP and OppA are the most abundant periplasmic proteins in E. coli K-12 and B strains (Han et al., 2014). These results suggest that at least several periplasmic substrate-binding proteins may also play roles in periplasmic proteostasis. However, their detailed molecular mechanisms and the physiological roles associated with their chaperone activities have not yet been elucidated. E. coli $\mathrm{MBP}$ is very widely used as a fusion tag to enhance the solubility of target recombinant proteins (Riggs, 2000). How an MBP-fusion tag increases the solubility of the target recombinant proteins is still unclear, but one possible explanation is that MBP functions as a cis-acting chaperone in the context of these fusions by binding to the aggregationprone folding intermediates of the fused protein and preventing their aggregation (Richarme and Caldas, 1997; Fox et al., 2001). Importantly, the ligand-binding cleft of MBP has a hydrophobic nature, and the substitution of certain hydrophobic residues in the cleft with charged residues dramatically reduces the solubility of proteins fused to these MBP mutants (Fox et al., 2001). The chaperone activity regions for OppA and DppA have not been precisely determined, but, interestingly, co-crystal structures of OppA and DppA with their substrate peptides have shown that the peptides are bound deep inside the cleft (Dunten and Mowbray, 1995; Sleigh et al., 1999). These results suggest that the core hydrophobic cleft region is crucial for the chaperone activities of these periplasmic substrate-binding proteins, as it seems to be for UgpB.

\section{CONCLUDING REMARKS}

Due to high affinity and low specificity of chaperone to their client proteins, chaperone activity needs to be finely regulated. If their activity is unregulated, their high affinity for the unfolded or partial-folded states may interfere with the folding process and thus be harmful to the cell. Many cytosolic chaperones utilize ATP to modulate their activity, but periplasmic chaperones require an alternative regulatory mechanism because the periplasmic space is completely lacking in ATP. To function as a chaperone during exposure to environmental stress in the periplasm, the expression level of the stress-responsive chaperones needs to be sensitively regulated. Spy, for example, is nearly absent during normal growth, but a massive induction of Spy occurs following envelope stress. In addition to regulating the expression level, periplasmic stress-responsive chaperones have a number of novel mechanisms to directly control their chaperone activities at the protein level. Spy fine-tunes its binding affinity for client proteins to enable them to fold while bound to Spy. DegP regulates its dual function as a chaperone and protease in response to temperature changes. $\mathrm{A}$ few of the periplasmic chaperones (e.g., HdeA, HdeB, and UgpB) take advantage of the external environmental changes associated with natural host physiology, such as the $\mathrm{pH}$ decline caused by the passage of bacteria through the stomach, to regulate chaperone activity. Low $\mathrm{pH}$ induces partial unfolding in HdeA and HdeB, activating their chaperone activities. Neutralization allows substrate release and the refolding of both the client and the chaperone. The bile-responsive chaperone $\operatorname{UgpB}$ also utilizes low $\mathrm{pH}$ as an environmental cue to activate UgpB as a chaperone. The low $\mathrm{pH}$ environment in the stomach strips off the bound G3P to activate the chaperone activity of $\operatorname{UgpB}$, thus enabling $\operatorname{UgpB}$ to suppress bile-induced protein aggregation in the duodenum. 


\section{AUTHOR CONTRIBUTIONS}

CL conceived and wrote the manuscript. HK and KW made figures and helped in the writing of the manuscript. All authors contributed to the article and approved the submitted version.

\section{FUNDING}

This work was funded by the Howard Hughes Medical Institute to James Bardwell, the National Research Foundation of Korea

\section{REFERENCES}

Ades, S. E., Grigorova, I. L., and Gross, C. A. (2003). Regulation of the alternative sigma factor sigma(E) during initiation, adaptation, and shutoff of the extracytoplasmic heat shock response in Escherichia coli. J. Bacteriol. 185, 2512-2519. doi: 10.1128/jb.185.8.2512-2519.2003

Alba, B. M., and Gross, C. A. (2004). Regulation of the Escherichia coli sigmadependent envelope stress response. Mol. Microbiol. 52, 613-619. doi: 10.1111/ j.1365-2958.2003.03982.x

Ames, G. F. (1986). Bacterial periplasmic transport systems: structure, mechanism, and evolution. Annu. Rev. Biochem. 55, 397-425. doi: 10.1146/annurev.bi.55. 070186.002145

Argast, M., and Boos, W. (1979). Purification and properties of the sn-glycerol 3phosphate-binding protein of Escherichia coli. J. Biol. Chem. 254, 10931-10935. doi: 10.1016/s0021-9258(19)86613-9

Arnqvist, A., Olsen, A., and Normark, S. (1994). Sigma S-dependent growth-phase induction of the csgBA promoter in Escherichia coli can be achieved in vivo by sigma 70 in the absence of the nucleoid-associated protein H-NS. Mol. Microbiol. 13, 1021-1032. doi: 10.1111/j.1365-2958.1994.tb00493.x

Bardwell, J. C. (1994). Building bridges: disulphide bond formation in the cell. Mol. Microbiol. 14, 199-205. doi: 10.1111/j.1365-2958.1994.tb01281.x

Bardwell, J. C., Mcgovern, K., and Beckwith, J. (1991). Identification of a protein required for disulfide bond formation in vivo. Cell 67, 581-589. doi: 10.1016/ 0092-8674(91)90532-4

Bednarska, N. G., Van Eldere, J., Gallardo, R., Ganesan, A., Ramakers, M., Vogel, I., et al. (2016). Protein aggregation as an antibiotic design strategy. Mol. Microbiol. 99, 849-865. doi: 10.1111/mmi.13269

Bennion, D., Charlson, E. S., Coon, E., and Misra, R. (2010). Dissection of betabarrel outer membrane protein assembly pathways through characterizing BamA POTRA 1 mutants of Escherichia coli. Mol. Microbiol. 77, 1153-1171. doi: 10.1111/j.1365-2958.2010.07280.x

Bernstein, C., Bernstein, H., Payne, C. M., Beard, S. E., and Schneider, J. (1999). Bile salt activation of stress response promoters in Escherichia coli. Curr. Microbiol. 39, 68-72. doi: 10.1007/s002849900420

Burby, P. E., Nye, T. M., Schroeder, J. W., and Simmons, L. A. (2017). Implementation and data analysis of Tn-seq, whole-genome resequencing, and single-molecule real-time sequencing for bacterial genetics. J. Bacteriol. 199, e00560-e00616.

Bury-Mone, S., Nomane, Y., Reymond, N., Barbet, R., Jacquet, E., Imbeaud, S., et al. (2009). Global analysis of extracytoplasmic stress signaling in Escherichia coli. PLoS Genet 5:e1000651. doi: 10.1371/journal.pgen.1000651

Cabral, D. J., Small, D. M., Lilly, H. S., and Hamilton, J. A. (1987). Transbilayer movement of bile acids in model membranes. Biochemistry 26, 1801-1804. doi: 10.1021/bi00381a002

Calabrese, A. N., Schiffrin, B., Watson, M., Karamanos, T. K., Walko, M., Humes, J. R., et al. (2020). Inter-domain dynamics in the chaperone SurA and multi-site binding to its outer membrane protein clients. Nat. Commun. 11:2155.

CastilloKeller, M., and Misra, R. (2003). Protease-deficient DegP suppresses lethal effects of a mutant OmpC protein by its capture. J. Bacteriol. 185, 148-154. doi: $10.1128 /$ jb.185.1.148-154.2003

Chang, Z. (2016). The function of the DegP (HtrA) protein: protease versus chaperone. IUBMB Life 68, 904-907. doi: 10.1002/iub.1561
(NRF) grant funded by the Korea government (MSIT) (No. 2021R1C1C1011690) and the new faculty research fund of Ajou University to Changhan Lee.

\section{ACKNOWLEDGMENTS}

We thank James Bardwell from the University of Michigan for helpful discussion and his extensive comments on the manuscript.

Clausen, T., Kaiser, M., Huber, R., and Ehrmann, M. (2011). HTRA proteases: regulated proteolysis in protein quality control. Nat. Rev. Mol. Cell. Biol. 12, 152-162. doi: 10.1038/nrm3065

Coyle, J. E., Jaeger, J., Gross, M., Robinson, C. V., and Radford, S. E. (1997). Structural and mechanistic consequences of polypeptide binding by GroEL. Fold Des. 2, R93-R104.

Cremers, C. M., Knoefler, D., Vitvitsky, V., Banerjee, R., and Jakob, U. (2014). Bile salts act as effective protein-unfolding agents and instigators of disulfide stress in vivo. Proc. Natl. Acad. Sci. U.S.A. 111, E1610-E1619.

Dahl, J. U., Koldewey, P., Salmon, L., Horowitz, S., Bardwell, J. C., and Jakob, U. (2015). HdeB functions as an acid-protective chaperone in bacteria. J. Biol. Chem. 290:9950. doi: 10.1074/jbc.a114.612986

Danese, P. N., Snyder, W. B., Cosma, C. L., Davis, L. J., and Silhavy, T. J. (1995). The Cpx two-component signal transduction pathway of Escherichia coli regulates transcription of the gene specifying the stress-inducible periplasmic protease. DegP. Genes Dev. 9, 387-398. doi: 10.1101/gad.9.4.387

Dill, K. A., and Shortle, D. (1991). Denatured states of proteins. Annu. Rev. Biochem. 60, 795-825. doi: 10.1146/annurev.bi.60.070191.00 4051

Ding, J., Yang, C., Niu, X., Hu, Y., and Jin, C. (2015). HdeB chaperone activity is coupled to its intrinsic dynamic properties. Sci. Rep. 5:16856.

Dudin, O., Lacour, S., and Geiselmann, J. (2013). Expression dynamics of RpoS/Crl-dependent genes in Escherichia coli. Res. Microbiol. 164, 838-847. doi: 10.1016/j.resmic.2013.07.002

Dunten, P., and Mowbray, S. L. (1995). Crystal structure of the dipeptide binding protein from Escherichia coli involved in active transport and chemotaxis. Protein Sci. 4, 2327-2334. doi: 10.1002/pro.5560041110

Flahaut, S., Frere, J., Boutibonnes, P., and Auffray, Y. (1996). Comparison of the bile salts and sodium dodecyl sulfate stress responses in Enterococcus faecalis. Appl. Environ. Microbiol. 62, 2416-2420. doi: 10.1128/aem.62.7.2416-2420. 1996

Foit, L., George, J. S., Zhang, B. W., Brooks, C. L. 3rd, and Bardwell, J. C. (2013). Chaperone activation by unfolding. Proc. Natl. Acad. Sci. U.S.A. 110, E1254-E1262.

Foit, L., Morgan, G. J., Kern, M. J., Steimer, L. R., Von Hacht, A. A., Titchmarsh, J., et al. (2009). Optimizing protein stability in vivo. Mol. Cell. 36, 861-871. doi: 10.1016/j.molcel.2009.11.022

Fox, J. D., Kapust, R. B., and Waugh, D. S. (2001). Single amino acid substitutions on the surface of Escherichia coli maltose-binding protein can have a profound impact on the solubility of fusion proteins. Protein Sci. 10, 622-630. doi: $10.1110 /$ ps.45201

Gajiwala, K. S., and Burley, S. K. (2000). HDEA, a periplasmic protein that supports acid resistance in pathogenic enteric bacteria. J. Mol. Biol. 295, 605-612. doi: 10.1006/jmbi.1999.3347

Gardner, S. G., Miller, J. B., Dean, T., Robinson, T., Erickson, M., Ridge, P. G., et al. (2015). Genetic analysis, structural modeling, and direct coupling analysis suggest a mechanism for phosphate signaling in Escherichia coli. BMC Genet. 16(Suppl. 2):S2. doi: 10.1186/1471-2156-16-S2-S2

Garrison, M. A., and Crowhurst, K. A. (2014). NMR-monitored titration of acidstress bacterial chaperone HdeA reveals that Asp and Glu charge neutralization produces a loosened dimer structure in preparation for protein unfolding and chaperone activation. Protein Sci. 23, 167-178. doi: 10.1002/pro.2402 
Gunasekera, T. S., Csonka, L. N., and Paliy, O. (2008). Genome-wide transcriptional responses of Escherichia coli K-12 to continuous osmotic and heat stresses. J. Bacteriol. 190, 3712-3720. doi: 10.1128/jb.01990-07

Gunn, J. S. (2000). Mechanisms of bacterial resistance and response to bile. Microbes Infect 2, 907-913. doi: 10.1016/s1286-4579(00)00392-0

Hagenmaier, S., Stierhof, Y. D., and Henning, U. (1997). A new periplasmic protein of Escherichia coli which is synthesized in spheroplasts but not in intact cells. J. Bacteriol. 179, 2073-2076. doi: 10.1128/jb.179.6.2073-2076.1997

Han, M. J., Kim, J. Y., and Kim, J. A. (2014). Comparison of the large-scale periplasmic proteomes of the Escherichia coli K-12 and B strains. J. Biosci. Bioeng. 117, 437-442. doi: 10.1016/j.jbiosc.2013.09.008

Hartl, F. U., Bracher, A., and Hayer-Hartl, M. (2011). Molecular chaperones in protein folding and proteostasis. Nature 475, 324-332. doi: 10.1038/ nature 10317

He, W., Zhang, J., Sachsenhauser, V., Wang, L., Bardwell, J. C. A., and Quan, S. (2020). Increased surface charge in the protein chaperone Spy enhances its antiaggregation activity. J. Biol. Chem. 295, 14488-14500. doi: 10.1074/jbc.ra119. 012300

Heaton, K. W. (1969). The importance of keeping bile salts in their place. Gut 10, 857-863. doi: 10.1136/gut.10.10.857

Hernandez, S. B., Cota, I., Ducret, A., Aussel, L., and Casadesus, J. (2012). Adaptation and preadaptation of Salmonella enterica to Bile. PLoS Genet. 8:e1002459. doi: 10.1371/journal.pgen.1002459

Hong, W., Wu, Y. E., Fu, X., and Chang, Z. (2012). Chaperone-dependent mechanisms for acid resistance in enteric bacteria. Trends Microbiol. 20, 328335. doi: 10.1016/j.tim.2012.03.001

Horowitz, S., Salmon, L., Koldewey, P., Ahlstrom, L. S., Martin, R., Quan, S., et al. (2016). Visualizing chaperone-assisted protein folding. Nat. Struct. Mol. Biol. 23, 691-697.

Ito, K., and Inaba, K. (2008). The disulfide bond formation (Dsb) system. Curr. Opin. Struct. Biol. 18, 450-458. doi: 10.1016/j.sbi.2008.02.002

Jiang, J., Zhang, X., Chen, Y., Wu, Y., Zhou, Z. H., Chang, Z., et al. (2008). Activation of DegP chaperone-protease via formation of large cage-like oligomers upon binding to substrate proteins. Proc. Natl. Acad. Sci. U.S.A. 105, 11939-11944. doi: 10.1073/pnas.0805464105

Kern, R., Malki, A., Abdallah, J., Tagourti, J., and Richarme, G. (2007). Escherichia coli HdeB is an acid stress chaperone. J. Bacteriol. 189, 603-610. doi: 10.1128/ jb.01522-06

Kim, S., Grant, R. A., and Sauer, R. T. (2011). Covalent linkage of distinct substrate degrons controls assembly and disassembly of DegP proteolytic cages. Cell 145, 67-78. doi: 10.1016/j.cell.2011.02.024

Kim, Y. E., Hipp, M. S., Bracher, A., Hayer-Hartl, M., and Hartl, F. U. (2013). Molecular chaperone functions in protein folding and proteostasis. Annu. Rev. Biochem. 82, 323-355. doi: 10.1146/annurev-biochem-060208-092442

Klebanoff, S. J., Kettle, A. J., Rosen, H., Winterbourn, C. C., and Nauseef, W. M. (2013). Myeloperoxidase: a front-line defender against phagocytosed microorganisms. J. Leukoc Biol. 93, 185-198. doi: 10.1189/jlb.0712349

Koldewey, P., Horowitz, S., and Bardwell, J. C. A. (2017). Chaperone-client interactions: non-specificity engenders multifunctionality. J. Biol. Chem. 292, 12010-12017. doi: 10.1074/jbc.r117.796862

Koldewey, P., Stull, F., Horowitz, S., Martin, R., and Bardwell, J. C. A. (2016). Forces driving chaperone action. Cell 166, 369-379. doi: 10.1016/j.cell.2016.05.054

Kouidmi, I., Alvarez, L., Collet, J. F., Cava, F., and Paradis-Bleau, C. (2018). The chaperone activities of DsbG and Spy restore peptidoglycan biosynthesis in the elyC mutant by preventing envelope protein aggregation. J. Bacteriol. 200, e00245-e00318.

Krojer, T., Garrido-Franco, M., Huber, R., Ehrmann, M., and Clausen, T. (2002). Crystal structure of DegP (HtrA) reveals a new protease-chaperone machine. Nature 416, 455-459. doi: 10.1038/416455a

Krojer, T., Sawa, J., Schafer, E., Saibil, H. R., Ehrmann, M., and Clausen, T. (2008). Structural basis for the regulated protease and chaperone function of DegP. Nature 453, 885-890. doi: 10.1038/nature07004

Kwon, E., Kim, D. Y., Gross, C. A., Gross, J. D., and Kim, K. K. (2010). The crystal structure Escherichia coli Spy. Protein Sci. 19, 2252-2259.

Lee, C., Betschinger, P., Wu, K., Zyla, D. S., Glockshuber, R., and Bardwell, J. C. (2020). A metabolite binding protein moonlights as a bile-responsive chaperone. EMBO J. 39:e104231.
Lee, C., Kim, H., and Bardwell, J. C. A. (2018). Electrostatic interactions are important for chaperone-client interaction in vivo. Microbiology (Reading) 164, 992-997. doi: 10.1099/mic.0.000676

Lennon, C. W., Thamsen, M., Friman, E. T., Cacciaglia, A., Sachsenhauser, V., Sorgenfrei, F. A., et al. (2015). Folding optimization in vivo uncovers new chaperones. J. Mol. Biol. 427, 2983-2994. doi: 10.1016/j.jmb.2015.05.013

Leverrier, P., Dimova, D., Pichereau, V., Auffray, Y., Boyaval, P., and Jan, G. (2003). Susceptibility and adaptive response to bile salts in Propionibacterium freudenreichii: physiological and proteomic analysis. Appl. Environ. Microbiol. 69, 3809-3818. doi: 10.1128/aem.69.7.3809-3818.2003

Li, S., Wang, R., Li, D., Ma, J., Li, H., He, X., et al. (2014). Thermal-triggerd proteinquake leads to disassembly of DegP hexamer as an imperative activation step. Sci. Rep. 4:4834.

Link, A. J., Robison, K., and Church, G. M. (1997). Comparing the predicted and observed properties of proteins encoded in the genome of Escherichia coli K-12. Electrophoresis 18, 1259-1313. doi: 10.1002/elps.1150180807

Lipinska, B., Fayet, O., Baird, L., and Georgopoulos, C. (1989). Identification, characterization, and mapping of the Escherichia coli htrA gene, whose product is essential for bacterial growth only at elevated temperatures. J. Bacteriol. 171, 1574-1584. doi: 10.1128/jb.171.3.1574-1584.1989

Lipinska, B., Zylicz, M., and Georgopoulos, C. (1990). The HtrA (DegP) protein, essential for Escherichia coli survival at high temperatures, is an endopeptidase. J. Bacteriol. 172, 1791-1797. doi: 10.1128/jb.172.4.1791-1797.1990

Malki, A., Le, H. T., Milles, S., Kern, R., Caldas, T., Abdallah, J., et al. (2008). Solubilization of protein aggregates by the acid stress chaperones HdeA and HdeB. J. Biol. Chem. 283, 13679-13687. doi: 10.1074/jbc.m800869200

Masuda, N., and Church, G. M. (2003). Regulatory network of acid resistance genes in Escherichia coli. Mol. Microbiol. 48, 699-712. doi: 10.1046/j.1365-2958.2003. 03477.x

Mates, A. K., Sayed, A. K., and Foster, J. W. (2007). Products of the Escherichia coli acid fitness island attenuate metabolite stress at extremely low $\mathrm{pH}$ and mediate a cell density-dependent acid resistance. J. Bacteriol. 189, 2759-2768. doi: 10.1128/jb.01490-06

McCoy, L. S., Xie, Y., and Tor, Y. (2011). Antibiotics that target protein synthesis. Wiley Interdiscip Rev. RNA 2, 209-232. doi: 10.1002/wrna.60

Merritt, M. E., and Donaldson, J. R. (2009). Effect of bile salts on the DNA and membrane integrity of enteric bacteria. J. Med. Microbiol. 58, 1533-1541. doi: 10.1099/jmm.0.014092-0

Misra, R., Castillokeller, M., and Deng, M. (2000). Overexpression of proteasedeficient DegP(S210A) rescues the lethal phenotype of Escherichia coli OmpF assembly mutants in a degP background. J. Bacteriol. 182, 4882-4888. doi: 10.1128/jb.182.17.4882-4888.2000

Mitra, R., Gadkari, V. V., Meinen, B. A., Van Mierlo, C. P. M., Ruotolo, B. T., and Bardwell, J. C. A. (2021). Mechanism of the small ATP-independent chaperone Spy is substrate specific. Nat. Commun. 12:851.

Miyawaki, S., Uemura, Y., Hongo, K., Kawata, Y., and Mizobata, T. (2019). Aciddenatured small heat shock protein HdeA from Escherichia coli forms reversible fibrils with an atypical secondary structure. J. Biol. Chem. 294, 1590-1601. doi: 10.1074/jbc.ra118.005611

Mogk, A., Bukau, B., and Kampinga, H. H. (2018). Cellular handling of protein aggregates by disaggregation machines. Mol. Cell 69, 214-226. doi: 10.1016/j. molcel.2018.01.004

Mogk, A., Ruger-Herreros, C., and Bukau, B. (2019). Cellular functions and mechanisms of action of small heat shock proteins. Annu. Rev. Microbiol. 73, 89-110. doi: 10.1146/annurev-micro-020518-115515

Neu, H. C., and Heppel, L. A. (1965). The release of enzymes from Escherichia coli by osmotic shock and during the formation of spheroplasts. J. Biol. Chem. 240, 3685-3692. doi: 10.1016/s0021-9258(18)97200-5

Nichols, R. J., Sen, S., Choo, Y. J., Beltrao, P., Zietek, M., Chaba, R., et al. (2011). Phenotypic landscape of a bacterial cell. Cell 144, 143-156. doi: 10.1016/j.cell. 2010.11.052

Nikaido, H. (2003). Molecular basis of bacterial outer membrane permeability revisited. Microbiol. Mol. Biol. Rev. 67, 593-656. doi: 10.1128/mmbr.67.4.593656.2003

Ortega, J., Iwanczyk, J., and Jomaa, A. (2009). Escherichia coli DegP: a structuredriven functional model. J. Bacteriol. 191, 4705-4713. doi: 10.1128/jb.00 472-09 
Pallen, M. J., and Wren, B. W. (1997). The HtrA family of serine proteases. Mol. Microbiol. 26, 209-221. doi: 10.1046/j.1365-2958.1997.5601928.x

Paradis-Bleau, C., Kritikos, G., Orlova, K., Typas, A., and Bernhardt, T. G. (2014). A genome-wide screen for bacterial envelope biogenesis mutants identifies a novel factor involved in cell wall precursor metabolism. PLoS Genet. 10:e1004056. doi: 10.1371/journal.pgen.1004056

Patel, G. J., and Kleinschmidt, J. H. (2013). The lipid bilayer-inserted membrane protein BamA of Escherichia coli facilitates insertion and folding of outer membrane protein A from its complex with Skp. Biochemistry 52, 3974-3986. doi: $10.1021 / \mathrm{bi400103t}$

Prieto, A. I., Ramos-Morales, F., and Casadesus, J. (2004). Bile-induced DNA damage in Salmonella enterica. Genetics 168, 1787-1794. doi: 10.1534/genetics. 104.031062

Quan, S., Koldewey, P., Tapley, T., Kirsch, N., Ruane, K. M., Pfizenmaier, J., et al. (2011). Genetic selection designed to stabilize proteins uncovers a chaperone called Spy. Nat. Struct. Mol. Biol. 18, 262-269. doi: 10.1038/nsmb.2016

Raffa, R. G., and Raivio, T. L. (2002). A third envelope stress signal transduction pathway in Escherichia coli. Mol. Microbiol. 45, 1599-1611. doi: 10.1046/j.13652958.2002.03112.x

Raivio, T. L., Laird, M. W., Joly, J. C., and Silhavy, T. J. (2000). Tethering of CpxP to the inner membrane prevents spheroplast induction of the cpx envelope stress response. Mol. Microbiol. 37, 1186-1197. doi: 10.1046/j.1365-2958.2000.02074.

Rhodius, V. A., Suh, W. C., Nonaka, G., West, J., and Gross, C. A. (2006). Conserved and variable functions of the sigmaE stress response in related genomes. PLoS Biol. 4:e2. doi: 10.1371/journal.pbio.0040002

Richarme, G., and Caldas, T. D. (1997). Chaperone properties of the bacterial periplasmic substrate-binding proteins. J. Biol. Chem. 272, 15607-15612. doi: 10.1074/jbc.272.25.15607

Richter, K., Haslbeck, M., and Buchner, J. (2010). The heat shock response: life on the verge of death. Mol. Cell. 40, 253-266. doi: 10.1016/j.molcel.2010. 10.006

Riggs, P. (2000). Expression and purification of recombinant proteins by fusion to maltose-binding protein. Mol. Biotechnol. 15, 51-63. doi: 10.1385/mb:15:1:51

Ruiz, L., Margolles, A., and Sanchez, B. (2013). Bile resistance mechanisms in Lactobacillus and Bifidobacterium. Front. Microbiol. 4:396. doi: 10.3389/fmicb. 2013.00396

Saibil, H. (2013). Chaperone machines for protein folding, unfolding and disaggregation. Nat. Rev. Mol. Cell Biol. 14, 630-642. doi: 10.1038/nrm3658

Salmon, L., Stull, F., Sayle, S., Cato, C., Akgul, S., Foit, L., et al. (2018). The mechanism of HdeA unfolding and chaperone activation. J. Mol. Biol. 430, 33-40. doi: 10.1016/j.jmb.2017.11.002

Sangurdekar, D. P., Srienc, F., and Khodursky, A. B. (2006). A classification based framework for quantitative description of large-scale microarray data. Genome Biol. 7:R32. doi: 10.1201/9781420094510-8

Schiffrin, B., Calabrese, A. N., Devine, P. W. A., Harris, S. A., Ashcroft, A. E., Brockwell, D. J., et al. (2016). Skp is a multivalent chaperone of outer-membrane proteins. Nat. Struct. Mol. Biol. 23, 786-793. doi: 10.1038/nsmb.3266

Schreiber, G., Haran, G., and Zhou, H. X. (2009). Fundamental aspects of proteinprotein association kinetics. Chem. Rev. 109, 839-860. doi: 10.1021/cr800373w

Selzer, T., and Schreiber, G. (1999). Predicting the rate enhancement of protein complex formation from the electrostatic energy of interaction. J. Mol. Biol. 287, 409-419. doi: 10.1006/jmbi.1999.2615

Sklar, J. G., Wu, T., Kahne, D., and Silhavy, T. J. (2007). Defining the roles of the periplasmic chaperones SurA, Skp, and DegP in Escherichia coli. Genes Dev. 21, 2473-2484. doi: 10.1101/gad.1581007

Skorko-Glonek, J., Laskowska, E., Sobiecka-Szkatula, A., and Lipinska, B. (2007). Characterization of the chaperone-like activity of HtrA (DegP) protein from Escherichia coli under the conditions of heat shock. Arch. Biochem. Biophys. 464, 80-89. doi: 10.1016/j.abb.2007.04.006

Skorko-Glonek, J., Wawrzynow, A., Krzewski, K., Kurpierz, K., and Lipinska, B. (1995). Site-directed mutagenesis of the HtrA (DegP) serine protease, whose proteolytic activity is indispensable for Escherichia coli survival at elevated temperatures. Gene 163, 47-52. doi: 10.1016/0378-1119(95)00406-v

Sleigh, S. H., Seavers, P. R., Wilkinson, A. J., Ladbury, J. E., and Tame, J. R. (1999). Crystallographic and calorimetric analysis of peptide binding to OppA protein. J. Mol. Biol. 291, 393-415. doi: 10.1006/jmbi.1999.2929
Spiess, C., Beil, A., and Ehrmann, M. (1999). A temperature-dependent switch from chaperone to protease in a widely conserved heat shock protein. Cell 97, 339-347. doi: 10.1016/s0092-8674(00)80743-6

Strauch, K. L., Johnson, K., and Beckwith, J. (1989). Characterization of degP, a gene required for proteolysis in the cell envelope and essential for growth of Escherichia coli at high temperature. J. Bacteriol. 171, 2689-2696. doi: 10.1128/ jb.171.5.2689-2696.1989

Stull, F., Betton, J. M., and Bardwell, J. C. A. (2018a). Periplasmic chaperones and prolyl isomerases. EcoSal Plus 8, doi: 10.1128/ecosalplus.ESP-00052018

Stull, F., Hipp, H., Stockbridge, R. B., and Bardwell, J. C. A. (2018b). In vivo chloride concentrations surge to proteotoxic levels during acid stress. Nat. Chem. Biol. 14, 1051-1058. doi: 10.1038/s41589-018-0143-z

Stull, F., Koldewey, P., Humes, J. R., Radford, S. E., and Bardwell, J. C. A. (2016). Substrate protein folds while it is bound to the ATP-independent chaperone Spy. Nat. Struct. Mol. Biol. 23, 53-58. doi: 10.1038/nsmb.3133

Šulskis, D., Thoma, J., and Burmann, B. M. (2020). Structural basis of DegPprotease temperature-dependent activation. biorxiv [preprint] doi: 10.1101/ 2020.07.14.202507

Szewczyk, J., and Collet, J. F. (2016). The journey of lipoproteins through the cell: one birthplace, multiple destinations. Adv. Microb. Physiol. 69, 1-50. doi: 10.1016/bs.ampbs.2016.07.003

Tapley, T. L., Franzmann, T. M., Chakraborty, S., Jakob, U., and Bardwell, J. C. (2010). Protein refolding by $\mathrm{pH}$-triggered chaperone binding and release. Proc. Natl. Acad. Sci. U.S.A. 107, 1071-1076. doi: 10.1073/pnas.09116 10107

Thompson, N. J., Merdanovic, M., Ehrmann, M., Van Duijn, E., and Heck, A. J. (2014). Substrate occupancy at the onset of oligomeric transitions of DegP. Structure 22, 281-290. doi: 10.1016/j.str.2013.11.010

Tian, W., Chen, C., Lei, X., Zhao, J., and Liang, J. (2018). CASTp 3.0: computed atlas of surface topography of proteins. Nucleic Acids Res. 46, W363-W367.

Tyedmers, J., Mogk, A., and Bukau, B. (2010). Cellular strategies for controlling protein aggregation. Nat. Rev. Mol. Cell Biol. 11, 777-788. doi: 10.1038/ nrm2993

Urdaneta, V., and Casadesus, J. (2017). Interactions between bacteria and bile salts in the gastrointestinal and hepatobiliary tracts. Front. Med. (Lausanne) 4:163. doi: $10.3389 /$ fmed.2017.00163

Valastyan, J. S., and Lindquist, S. (2014). Mechanisms of protein-folding diseases at a glance. Dis. Model Mech. 7, 9-14. doi: 10.1242/dmm.013474

Van Den Berg, B., Clemons, W. M. Jr., Collinson, I., Modis, Y., Hartmann, E., Harrison, S. C., et al. (2004). X-ray structure of a protein-conducting channel. Nature 427, 36-44.

Van Opijnen, T., Bodi, K. L., and Camilli, A. (2009). Tn-seq: highthroughput parallel sequencing for fitness and genetic interaction studies in microorganisms. Nat. Methods 6, 767-772. doi: 10.1038/nmeth.1377

Wang, D., and Fierke, C. A. (2013). The BaeSR regulon is involved in defense against zinc toxicity in E. coli. Metallomics 5, 372-383. doi: 10.1039/ c3mt20217h

Wang, W., Rasmussen, T., Harding, A. J., Booth, N. A., Booth, I. R., and Naismith, J. H. (2012). Salt bridges regulate both dimer formation and monomeric flexibility in $\mathrm{HdeB}$ and may have a role in periplasmic chaperone function. J. Mol. Biol. 415, 538-546. doi: 10.1016/j.jmb.2011.11.026

Wanner, B. L. (1996). Phosphorus Assimilation and Control of the Phosphate Regulon. In Escherichia coli and Salmonella. Washington, DC: American Society for Microbiology.

Waterman, S. R., and Small, P. L. (1996). Identification of sigma S-dependent genes associated with the stationary-phase acid-resistance phenotype of Shigella flexneri. Mol. Microbiol. 21, 925-940. doi: 10.1046/j.1365-2958.1996.00058.x

Weski, J., and Ehrmann, M. (2012). Genetic analysis of 15 protein folding factors and proteases of the Escherichia coli cell envelope. J. Bacteriol. 194, 3225-3233. doi: $10.1128 / \mathrm{jb} .00221-12$

Wu, K., Stull, F., Lee, C., and Bardwell, J. C. A. (2019). Protein folding while chaperone bound is dependent on weak interactions. Nat. Commun. 10:4833.

Wuttge, S., Bommer, M., Jager, F., Martins, B. M., Jacob, S., Licht, A., et al. (2012). Determinants of substrate specificity and biochemical properties of the sn-glycerol-3-phosphate ATP binding cassette transporter (UgpB-AEC2) of Escherichia coli. Mol. Microbiol. 86, 908-920. doi: 10.1111/mmi.12025 
Yang, F., Gustafson, K. R., Boyd, M. R., and Wlodawer, A. (1998). Crystal structure of Escherichia coli HdeA. Nat. Struct. Biol. 5, 763-764. doi: 10.1038/ 1796

Yu, X. C., Hu, Y., Ding, J., Li, H., and Jin, C. (2019). Structural basis and mechanism of the unfolding-induced activation of HdeA, a bacterial acid response chaperone. J. Biol. Chem. 294, 3192-3206. doi: 10.1074/jbc.ra118. 006398

Zhang, M., Lin, S., Song, X., Liu, J., Fu, Y., Ge, X., et al. (2011). A genetically incorporated crosslinker reveals chaperone cooperation in acid resistance. Nat. Chem. Biol. 7, 671-677. doi: 10.1038/nchembio.644
Conflict of Interest: The authors declare that the research was conducted in the absence of any commercial or financial relationships that could be construed as a potential conflict of interest.

Copyright (c) $2021 \mathrm{Kim}, \mathrm{Wu}$ and Lee. This is an open-access article distributed under the terms of the Creative Commons Attribution License (CC BY). The use, distribution or reproduction in other forums is permitted, provided the original author(s) and the copyright owner(s) are credited and that the original publication in this journal is cited, in accordance with accepted academic practice. No use, distribution or reproduction is permitted which does not comply with these terms. 